\title{
TELECOMMUNICATIONS CABLE COMBUSTION CHARACTERISTICS IN TUNNELS
}

\author{
Fumio HAYASHI, Takanobu WATANABE \\ Outside Plant Engineering Group, Tsukuba Engineering Development Center, NTT \\ 1-7-1, Hanabatake, Oho, Tsukuba Science City, Ibaraki, 305 Japan
}

(Received, December 20, 1985)

\begin{abstract}
In order to study telecommunications cable combustion characteristics, a $100 \mathrm{~m}$ long, ventilated full-scale tunnel was constructed to facilitate measurement of the temperatures inside the tunnel and those of its wall as well the velocities of two-layer countercurrents. Experimental results showed that the temperature distribution along the length of the tunnel was linear on logarithmic temperature. More than $80 \%$ of the dissipated calories obtained from the results were seen to be absorbed into the tunnel wall, and over $10 \%$ of the dissipated calories escaped as a gas flow out of the tunnel.

It was further found that a great volume of ethylene gas, which was generated from polyethylene cable sheath by heat decomposition, was included in the flow of the fire products. This gas did not burn because air-inflow from the tunnel fan was observed to be limited. Measured temperatures inside the tunnel indicated that polyethylene ignition point temperatures were never exceeded beyond about $40 \mathrm{~m}$ downstream of the burned end of the cables. A $40 \mathrm{~m}$ long fire-proof cable compartment design was evaluated and found to be effective in stopping the fire spread along an unenclosed upstream segment of cable bundle.
\end{abstract}

\section{INTRODUCTION}

The telecommunications cable fire, which occurred in the Tokyo Setagaya Telephone Office tunnel in November 1984, had a great impact on local and nation-wide social and economic activities. 100 cables burned for $160 \mathrm{~m}$ and approximately 90,000 telephone circuits were damaged. It took more than 16 hours to extinguish the fire. This incident clarified that it would be necessary to take immediate measures to prevent or limit damage that might be caused by tunnel cable fires in the future.

Present telecommunications line tunnels generally accomodate a great deal of polyethylene-sheathed cable. Hence, there is a particularly severe fire potential. It is accordingly important to study tunnel inside temperature distribution caused by such a cable fire, in order to prevent the future spread of fire. Up to now, there have been found many studies ${ }^{(1),(2)}$ on flow behaviors of hot fire products, however, studies on fires like the Setagaya Office tunnel cable fire have not been fully done. Therefore, full-scale cable combustion experiments were carried out using an experimental tunnel $2.25 \mathrm{~m}$ in height, $2.45 \mathrm{~m}$ in width and $100 \mathrm{~m}$ 


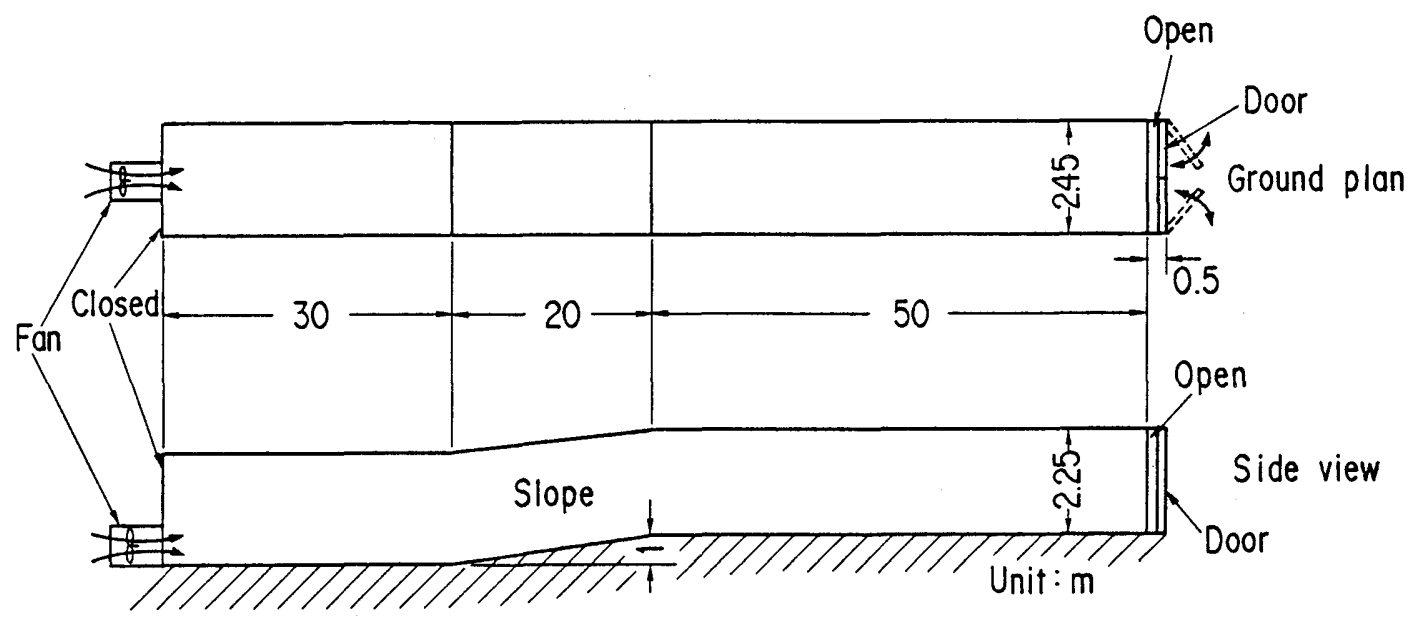

Fig. 1 Experimental tunnel

in length. It was constructed aboveground.

Temperatures inside the tunnel and those of the wall were measured using an array of thermocouples. Two-layer current velocities were also measured in the vicinity of the tunnel exit. Using the results obtained from these measurements, calorie analysis was performed.

\section{EXPERIMENT}

The 100 meter-long reinforced concrete tunnel with a rectangular cross section that was constructed aboveground is shown in Fig. 1. Internally $2.45 \mathrm{~m}$ in width and $2.25 \mathrm{~m}$ in height, the tunnel was full-scale and was able to accomodate a maximum of 80 cables. The wall thickness was $150 \mathrm{~mm}$ along the horizontal parts and $200 \mathrm{~mm}$ along the slope. Many actual tunnels have such slopes.

Two experiments were carried out as shown in Fig. 2. Cables, $60 \sim 70 \mathrm{~mm}$ in diameter, with $1,000 \sim 2,000$ pairs were laid in the tunnel. A piece of rag moistened by $1 \sim 2$ liters of gasoline was put on the cable of the lowest rack and used to ignite the cable. A fan was fixed at the one end of the tunnel to produce an air speed of $0.5 \mathrm{~m} / \mathrm{s}$ in the tunnel, which is the average speed in an actual tunnel, prior to ignition. An iron door was installed $0.5 \mathrm{~m}$ apart from the other end of the tunnel.

In the first experiment, 80 cables, each $10 \mathrm{~m}$ in length, were placed toward the end of the tunnel and burned to measure temperature distributions inside the tunnel with the door closed. Also, 15 cable segments, were arranged a height of $2.2 \mathrm{~m}$ and at intervals of $5 \mathrm{~m}$ along the tunnel in order to investigate the relationships between cable surface temperature and cable sheath appearance. Each cable segment $1.2 \mathrm{~m}$ in length was laid on the cable racks with the span of $1.0 \mathrm{~m}$.

In the second experiment, the total volume of cables burned with the door open was 2.5 times larger than that of the first experiment. The potential prevention of fire spread by means of $40 \mathrm{~m}$ fireproof sections was investigated. As a fire-proof compartment, there were used four kinds of materials, namely, steel sheet boxes filled with rock wool, anti-heat glass cloth filled with ceramic 


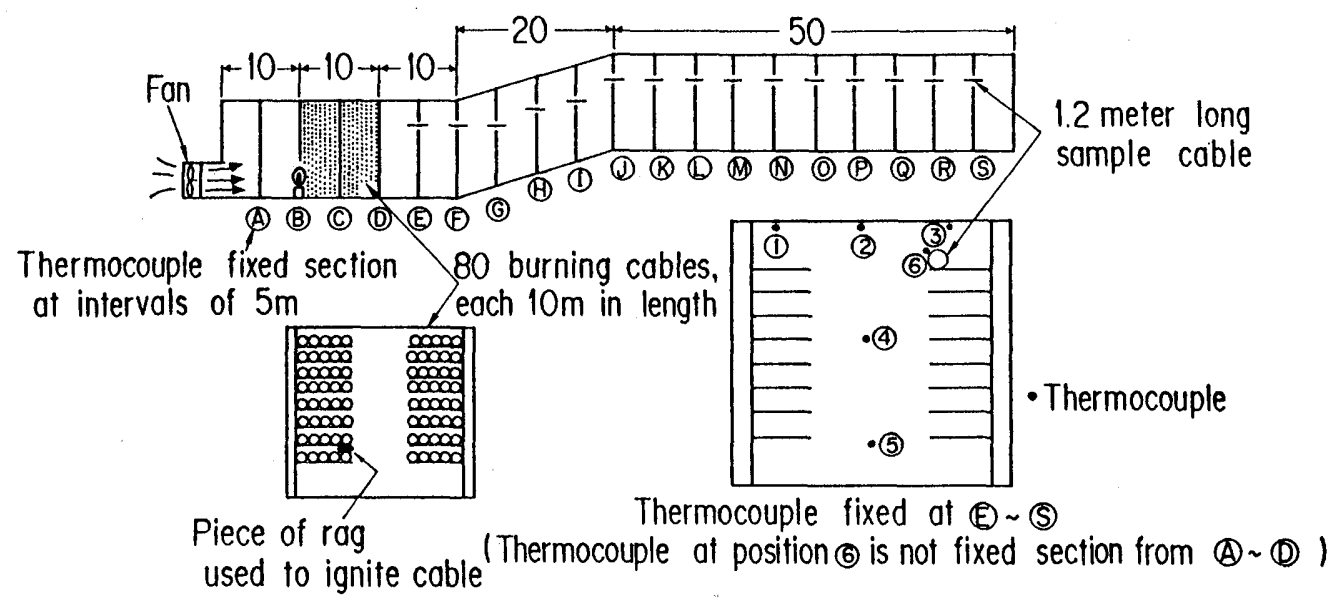

(1) Experiment No.1 (Side view)

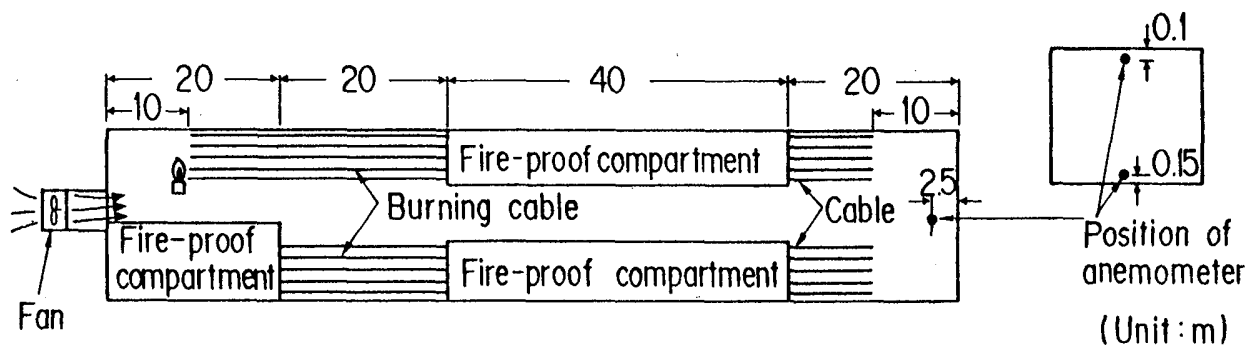

(2) Experiment No.2 (Ground view)

Fig. 2 Layout for cable combustion experiment

fiber, autoclaved light weight concrete boads and tri-calcium silicate boads. In addition to the temperature inside the tunnel, tunnel wall temperatures on the cable inside the fire-proof compartment and velocities for two-layer countercurrents in the vicinity of the tunnel exit were measured in this second experiment.

Both experiments were confined for ten hours, at which time there was indication that all elements of the tunnel system were well into a cool-down condition.

Chromel-Alumel thermocouples were used for temperature measurements. In the first experiment, 5 or 6 thermocouples were arranged at intervals of $5 \mathrm{~m}$, as shown in Fig. 2-(1). In addition, a thermocouple was fixed on the surface of each cable segment $1.2 \mathrm{~m}$ in length. In the second experiment, thermocouples were arranged by distances of $2 \sim 5 \mathrm{~m}$ in such positions as shown in Fig. $2-(1)$, and set up in the wall by boring from the outside at the positions shown in Fig. 3. The number of thermocouples was 5 at each position $\mathrm{a}, \mathrm{b}, \alpha$ and $\mathrm{B}$, and was 4 for $\mathrm{c} \sim \mathrm{f}, \gamma$ and $\delta$. Two anemometers were used to measure expected two-layer countercurrent velocities near the tunnel exit, as shown in Fig. 2-(2).

The temperature measurement system consisted of a scanner, a micro-computer, a CRT display as a monitor and a flopy disc driver as a recorder. Signals from each measuring points were scanned respectively at 

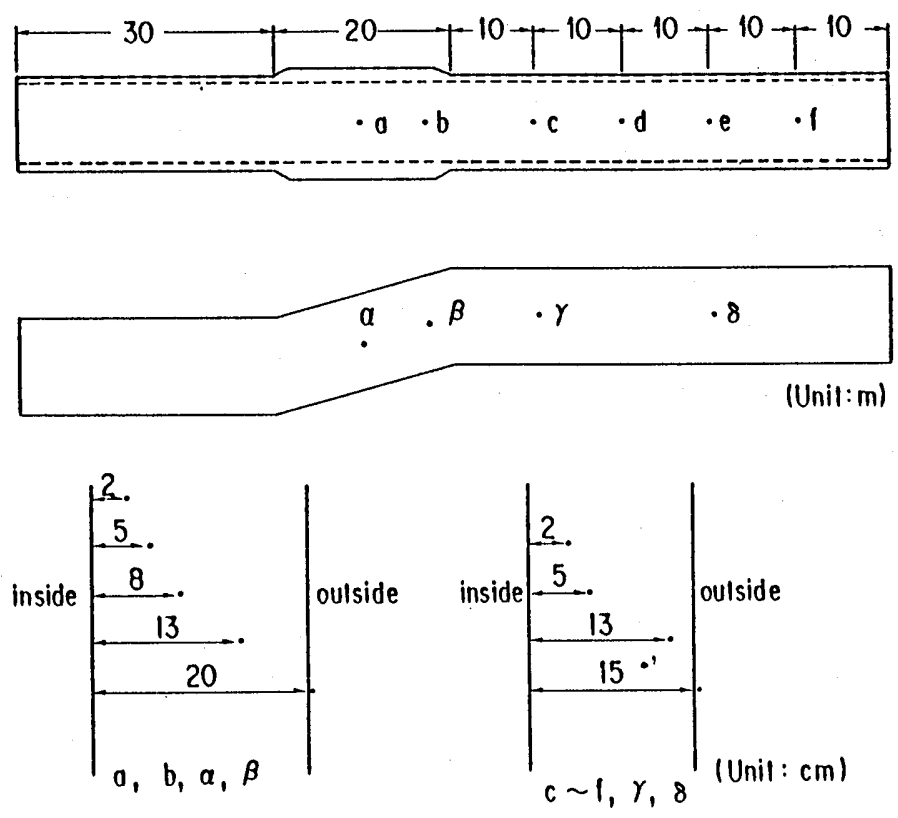

Fig. 3 Positions of thermocouples set up in wall

intervals of 30 seconds.

\section{RESULT}

The temperature distribution $5 \mathrm{~cm}$ below the upper wall inside the tunnel is shown in Figs. 4-(1), (2). These figures illustrate the temperature distribution in relation to distance and time. With the growth of cable's flame, polyethylene cable sheath began to drip with flame, which accelerated the spread of fire. The flame gradually creeped along the ceiling, and it took only $2 \sim 3$ minutes for the flame to spread from one side group of cable to the other side in the first experiment. The maximum temperature and time required were $905^{\circ} \mathrm{C}$ and 5 minutes in the first experiment, and $950^{\circ} \mathrm{C}$ and 20 minutes in the second experiment. Most of all cable burned down in an hour in the both experiments. 


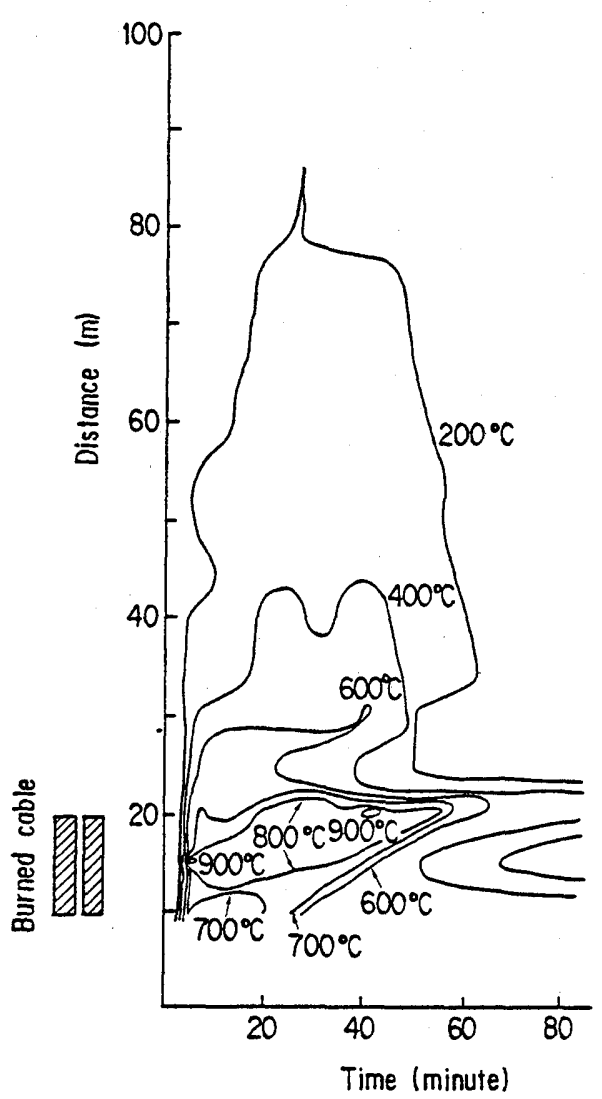

(1) Experiment No. 1

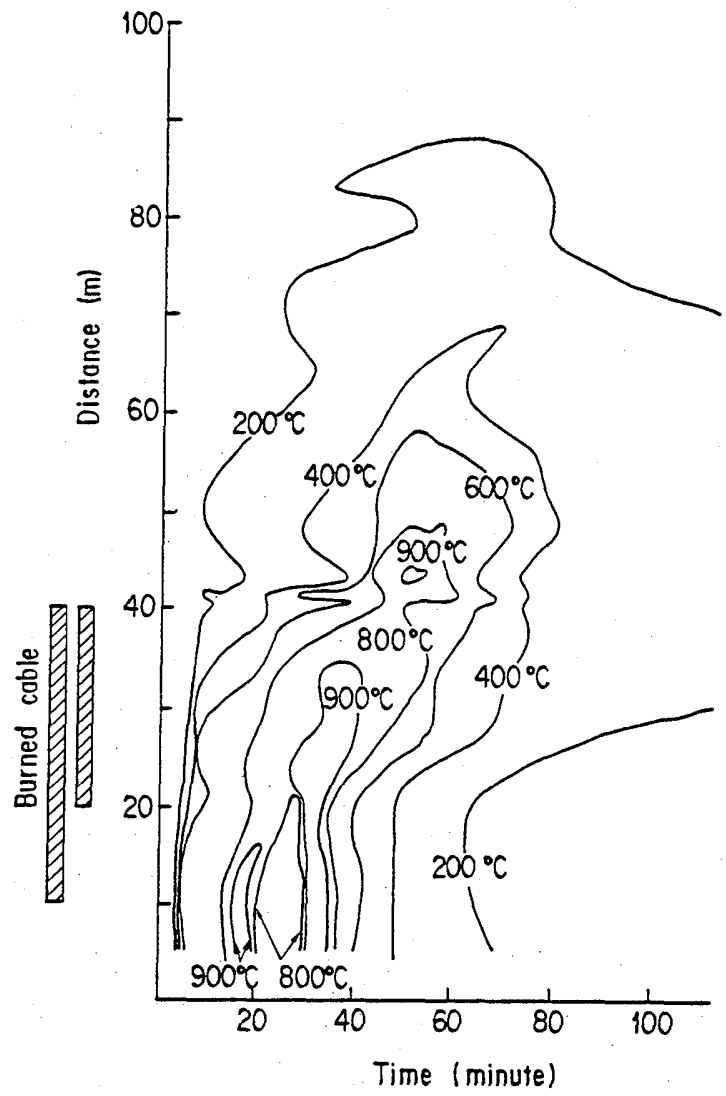

(2) Experiment No. 2

Fig. 4 Temperature inside tunnel near upper wall as function of distance and time

Figs. 5-(1), (2) indicate that the farthest downstream position in the tunnel where the temperature was above the polyethylene ignition point was about $30 \mathrm{~m}$ and $40 \mathrm{~m}$ downstream from the burned end of cables in the first and second experiments, respectively.

It can be seen in the second experiment that the temperature drops abruptly near $53 \mathrm{~m}$, and increases in the neighborhood of $58 \mathrm{~m}$ (See Fig. 5-(2)). The reason for this is considered that the heat flow along the slope impinged on the horizontal upper wall first, flowed downwards and then rose again. This is suggested from the fact that a part of the upper wall surface dropped due to heat stress. It did not occur in the first experiment.

The results presented in Fig. 5 show that the temperature distribution for the inside upper part of the tunnel, downstream of the burned end of the cable and for at least $40 \mathrm{~m}$, can be expressed linearly on a log temperature plot as shown in Fig. 6. The temperature gradients for the inside of the tunnel in both experiments are the same. 


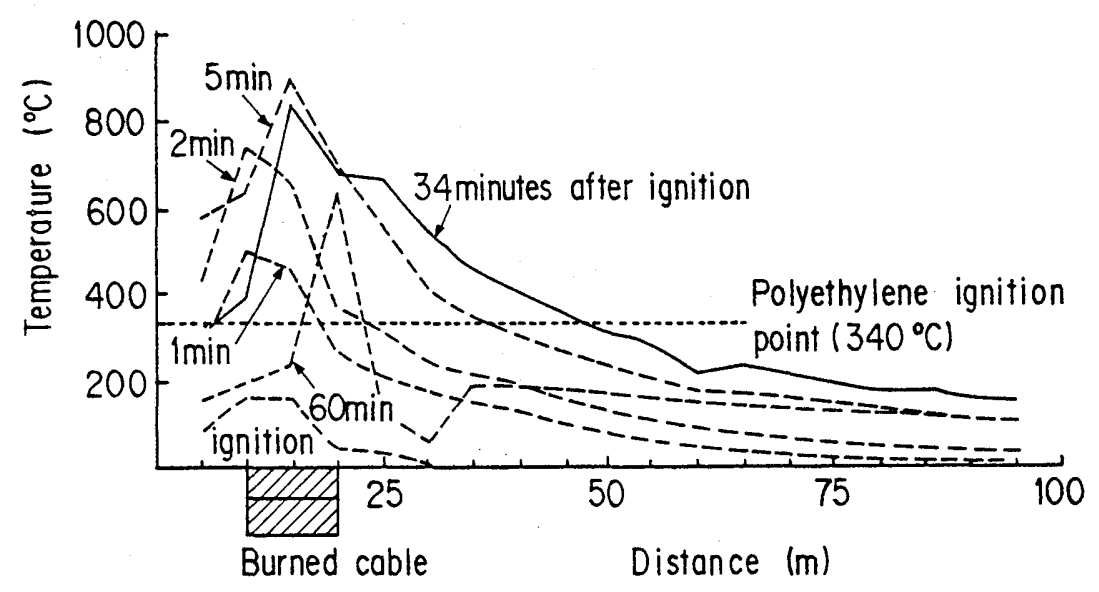

(1) Experiment No.1

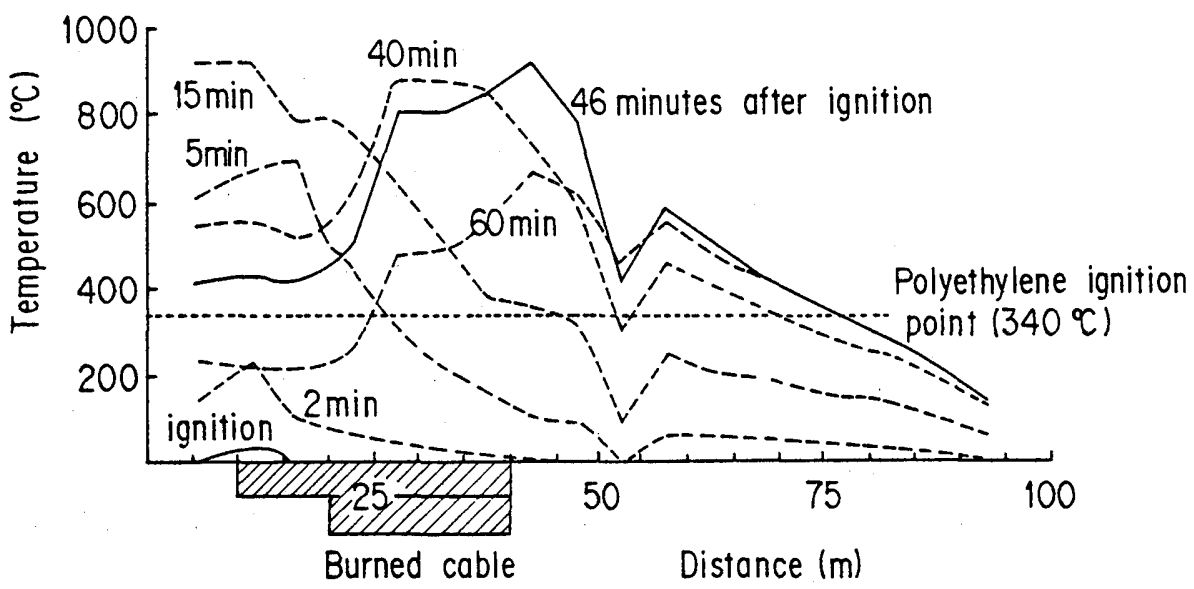

(2) Experiment No.2

Fig. 5 Temperature distribution under ceiling

In the first and second experiments, the temperatures near the tunnel exit were higher and lower, respectively than their corresponding straight line in Fig. 6 . The fact that the door at the tunnel exit was closed and open in the first and second experiments, respectively, no doubt had a significant influence on this result.

The temperature difference between out- side and inside the fire-proof compartment were $100 \sim 200^{\circ} \mathrm{C}$, and the temperature of polyethylene cable sheath exceeded its ignition point. However, the cable never burned inspite of decomposition of polyethylene. This is because there was lack of oxygen inside the fire-proof compartment. Thus, the compartment proved to work effectively.

Examples of cable surface temperature 


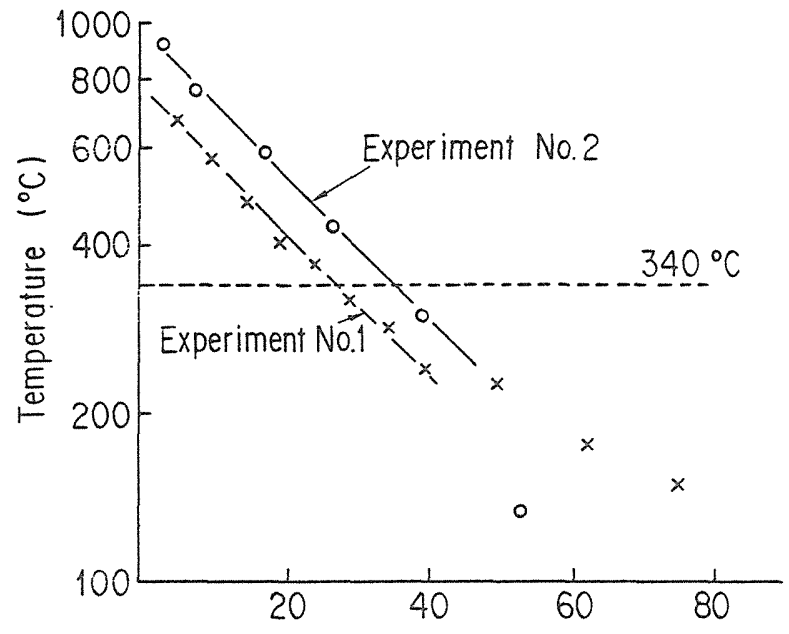

Distance from the burned cable end $(\mathrm{m})$

Fig. 6 Temperature distribution under ceiling on a logarithmic scale

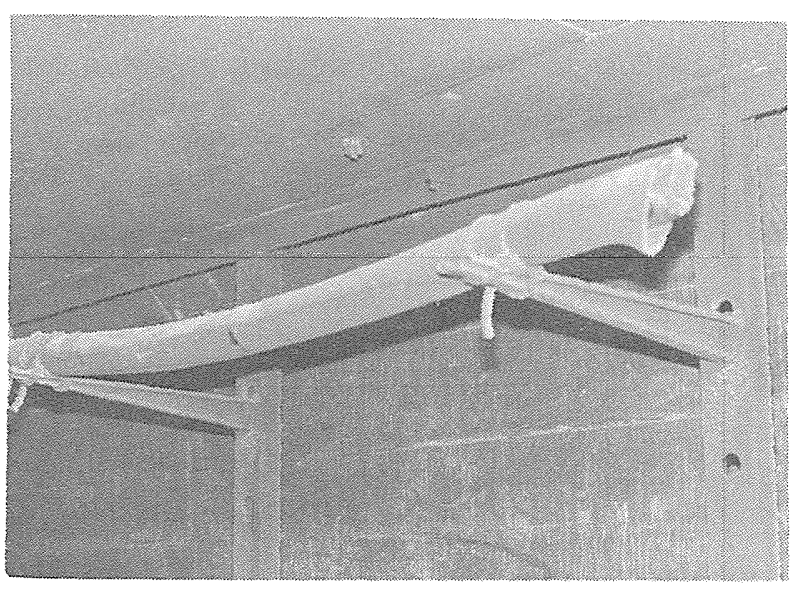

(1) $35 \mathrm{~m}$ from burned end of cable (Point K)

Photo 1 Sample of cable appearance

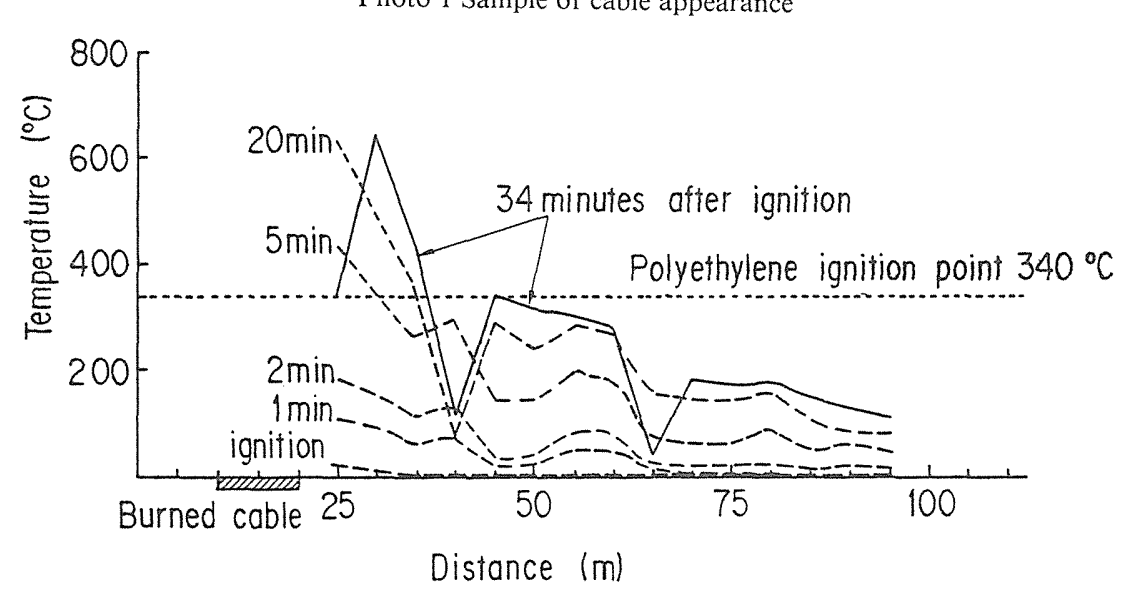

Fig. 7 Cable surface temperature of samples (Experiment

No. 1) distribution during the first experiment are shown in Fig. 7. Samples of the cable surface appearance are presented in Photo 1. It was confirmed that sample cables exposed to surface temperatures over $340^{\circ} \mathrm{C}$ burned down, and that the cable sheath in the $200 \sim 340^{\circ} \mathrm{C}$ region melted as shown in Photo 1-(1).

Tunnel wall temperatures relative to the thickness are shown in Fig. 8 and the distance in Fig. 9.

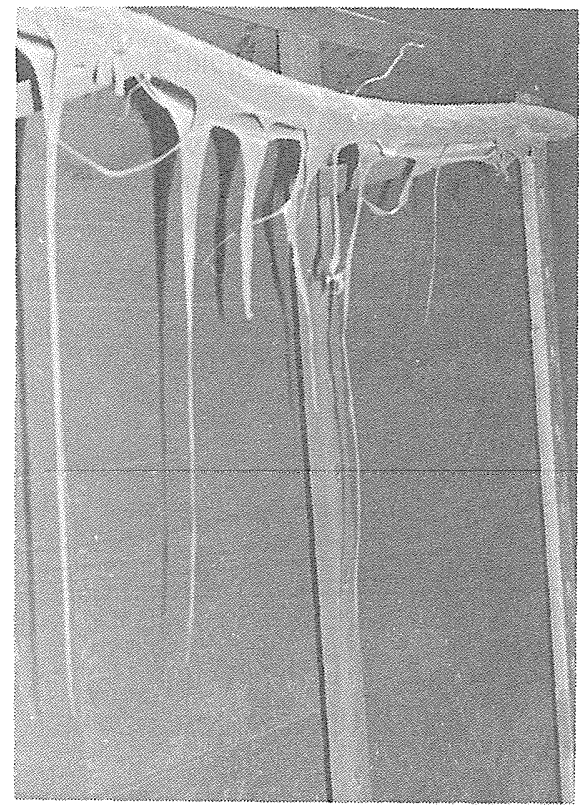

(2) $70 \mathrm{~m}$ from burned end of cable (Point R) 


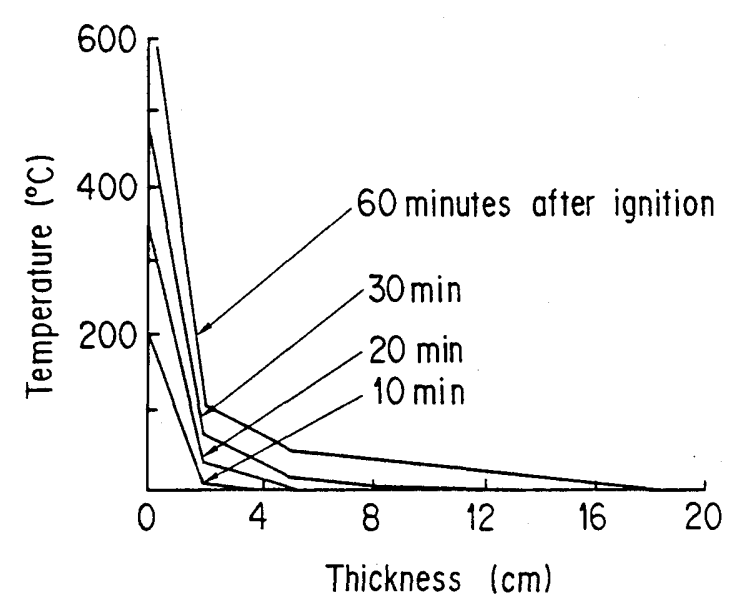

(1) Upper wall (a point)

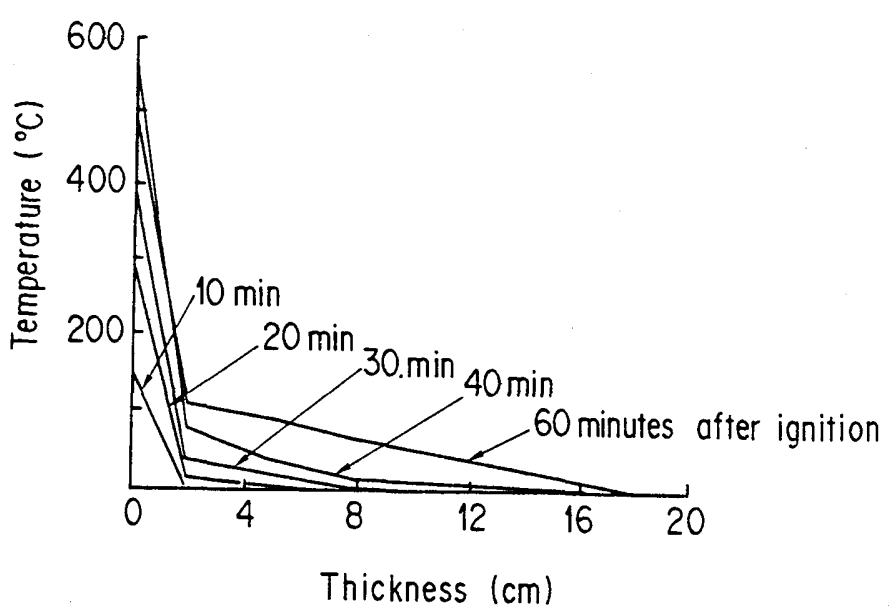

(2) Side wall (a point)

Fig. 8 Wall temperature distribution in tunnel wall for second experiment in relation to wall thickness

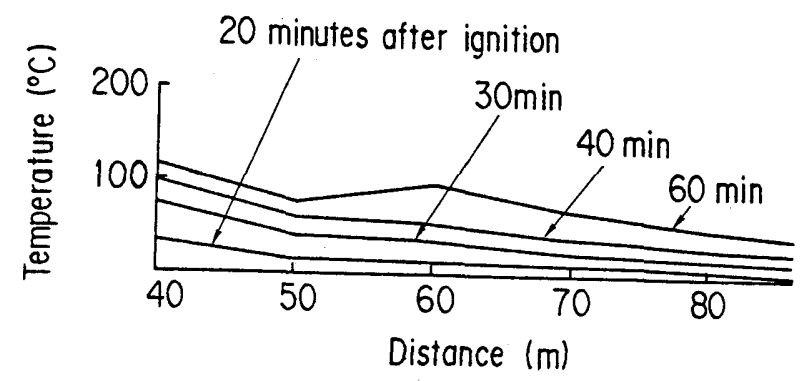

(1) Upper wall

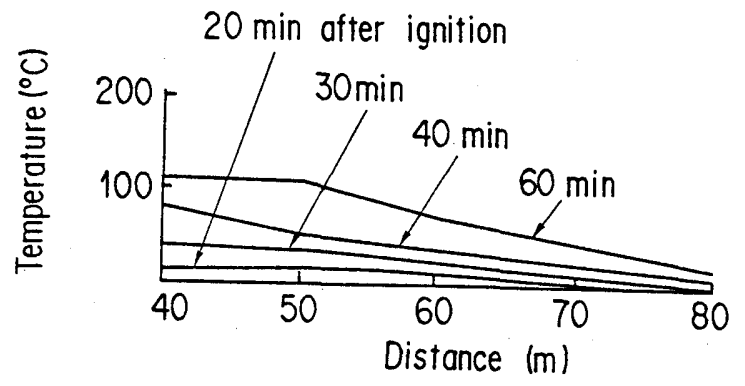

(2) Side wall

Fig. 9 Wall temperature distribution in tunnel length direction ( $2 \mathrm{~cm}$ from inside surface)

As indicated in Fig. 8, significant temperature gradients in the tunnel walls were confined to the inside $2 \mathrm{~cm}$. In addition, no significant temperature increases appeared near the outside surface within an hour after ignition. The wall temperature gradient at the point $2 \mathrm{~cm}$ from the inside surface in Fig. 9 was gentle in the length direction, in contrast to the temperature distribution inside the tunnel in Fig. 5.
Two-layer countercurrent velocities during the second experiment and at anemometer locations of Fig. 2 are shown in Fig. 10, where the upper current thickness was observed approximately $0.8 \mathrm{~m}$ at the tunnel exit. At these measured locations, the upper current velocity reached a maximum of $3.4 \mathrm{~m} / \mathrm{s}$ about 45 minutes after ignition. The lower current, however, flowed at almost constant speed of $0.3 \sim 0.5 \mathrm{~m} / \mathrm{s}$. 


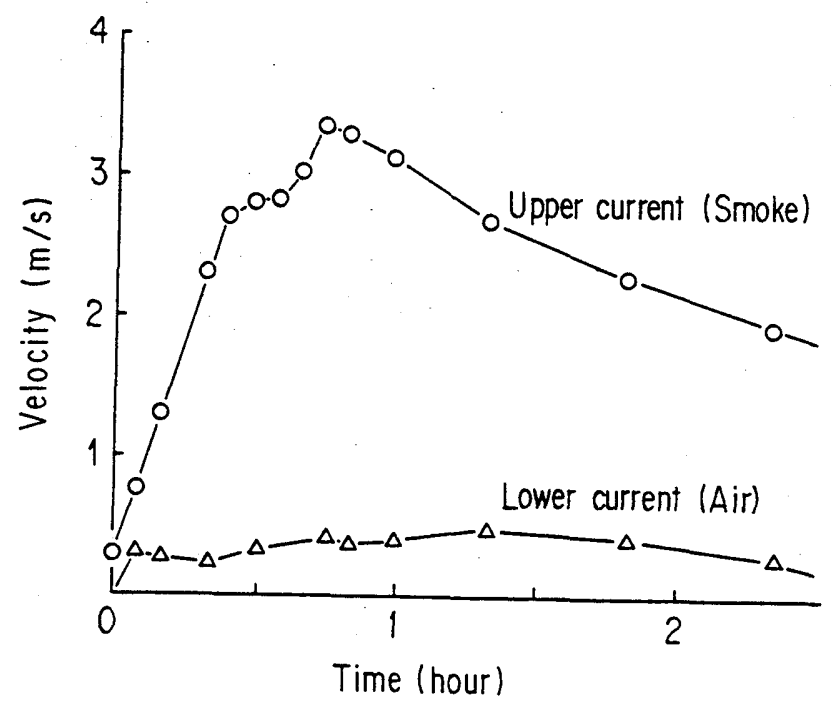

Fig. 10 Two-layer countercurrent velocities (Second experiment)

\section{DISCUSSION}

Calorie analysis and an extension of the results to study of the temperature distribution inside an actual tunnel were carried out based on the experimental results just presented.

\section{Calorie analysis}

The calorie-balance was calculated from the calories generated by cable combustin as well as the dissipated calories illustrated in Fig. 11.

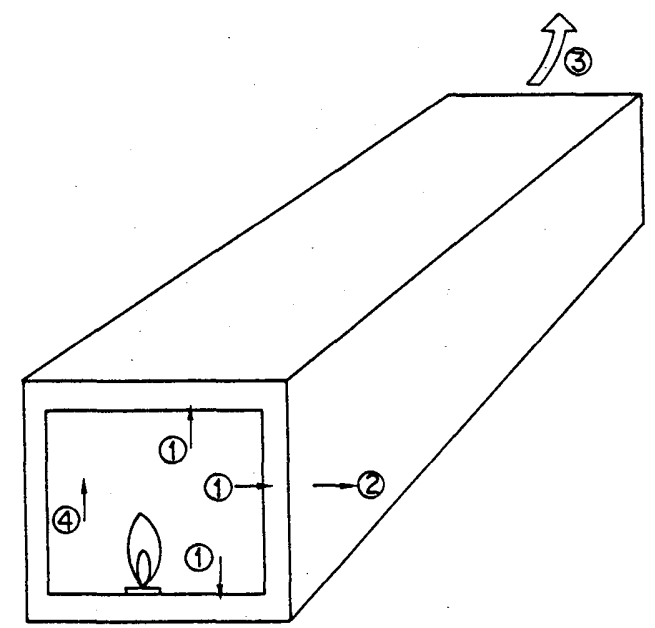

(1) Calories absorbed into tunnel wall, etc.

(2) Calories emitted from outside wall

(3) Calories carried away in gas flow out of tunnel

(4) Calories absorbed in air inside tunnel

Fig. 11 Dissipated calories model

This calorie-balance calculation was carried out for an hour after cable ignition. One hour was considered optimum, because in that time cables were almost completely burned. In addition, the amount of calories emitted from the outside wall was negligible on account of no temperature increases near the outside surface in an hour after cable 
ignition (See Fig. 8). Therefore, the dissipated calories contained no calories emitted from the outside wall.

Calories absorbed into the tunnel wall, etc., include those absorbed by fire-proof compartments and cable conductors. These calories were calculated using their heat capacities and the temperatures registerd at the thermocouples (See Figs. 8, 9). Tunnel wall calories in the first experiment were estimated on the basis of the data given in these two figures. Calories carried away in gas flow were obtained from its temperatures, velocities and current thickness described above and in Fig. 10.
The calorie value of polyethylene cable sheath and conductor insulation is 11,000 $\mathrm{kcal} / \mathrm{kg}$. Decomposition of polyethylene without combustion is estimated to be 2,450 $\mathrm{kcal} / \mathrm{kg}$. Calorie-dissipation data obtained from the relation between generated and dissipated calories are shown in Table 1. Potential calories, which consist of generated calories and calories included in smoke in the state of ethylene gas, present calories generated when all the polyethylene completely burns. The calories that the unburned ethylene gas contained was calculated as the difference between the potential and the generated calories.

Table 1. Calorie Analysis Results

\begin{tabular}{|c|c|c|c|c|c|c|}
\hline \multicolumn{3}{|l|}{ Calories } & \multicolumn{2}{|c|}{ No. 1} & \multicolumn{2}{|c|}{ No. 2} \\
\hline \multirow{3}{*}{$\begin{array}{l}\text { Potential* } \\
\text { calories }\end{array}$} & \multicolumn{2}{|c|}{$\begin{array}{l}\text { Calories included in smoke } \\
\text { in state of ethylene gas } \\
\text { carried away without combustion }\end{array}$} & \multirow{3}{*}{3.30} & 0.57 & \multirow{3}{*}{8.30} & 3.73 \\
\hline & \multirow{2}{*}{$\begin{array}{l}\text { Generated } \\
\text { calories }\end{array}$} & $\begin{array}{l}\text { Calories used to } \\
\text { decompose poly- } \\
\text { ethylene }\end{array}$ & & 0.13 & & 0.82 \\
\hline & & Dissipated calories & & 2.60 & & 3.75 \\
\hline \multirow{3}{*}{$\begin{array}{l}\text { Dissipated } \\
\text { calories }\end{array}$} & \multicolumn{2}{|c|}{$\begin{array}{l}\text { (1) Calories absorbed } \\
\text { into tunnel wall, etc. }\end{array}$} & $2.25(87)$ & \multirow{3}{*}{2.60} & $3.13(83)$ & \multirow{3}{*}{3.75} \\
\hline & \multicolumn{2}{|c|}{$\begin{array}{l}\text { (2) Calories carried away } \\
\text { in gas flow out of } \\
\text { tunnel }\end{array}$} & $0.32(12)$ & & $0.58(15)$ & \\
\hline & \multicolumn{2}{|r|}{$\begin{array}{l}\text { ries absorbed } \\
\text { inside tunnel }\end{array}$} & $0.03(1)$ & & $0.04(1)$ & \\
\hline
\end{tabular}

Unit: $10^{6} \mathrm{kcal} \quad(\quad)$ \% occupied by dissipated calories.

* Calories generated when all the polyethylene included in the cable decomposes and burns.

The rate of increase of generated calories in the second experiment was no more than $67 \%$ of that in the first experiment. The volume of unburned gas carried away in the second experiment was, therefore, about 6.5 times as great as that in the first experiment.
The proportion of dissipated calories is almost equal in both experiments. Calories absorbed into the tunnel wall represented over $80 \%$, because of the many pieces of dispersed within the tunnel and because the generated gas layer was sufficiently mixed 
by the tunnel fan and heat transfer was efficiently carried out. On the other hand, the number of calories carried away as gas flow was at most between 10 and $20 \%$ of the dissipated calories.

\section{Verification of calorie analysis results in second experiment}

The calorie analysis results can be verified by comparing the relation between the volume of gas calculated from a thermochemical reaction equation for ethylene gas and the volume of gas obtained from the two-layer countercurrent velocities in the second experiment.

The above-mentioned equation can be expressed as

$$
\mathrm{C}_{2} \mathrm{H}_{4}+3 \mathrm{O}_{2} \rightarrow 2 \mathrm{CO}_{2}+2 \mathrm{H}_{2} \mathrm{O}+337 \mathrm{kcal} / \mathrm{kg} \text {. }
$$

Using this equation for the results of the second experiment, the sum of gas volume of $\mathrm{CO}_{2}$ and $\mathrm{H}_{2} \mathrm{O}$ generated by the 4.57 million kcal described in Table 1 becomes $1.7 \times$ $10^{3} \mathrm{~m}^{3}$. The ethylene gas volume carried away without combustion is $0.4 \times 10^{3} \mathrm{~m}^{3}$. They total $2.1 \times 10^{3} \mathrm{~m}^{3}$.

The difference between the outflow, including gas generated by combustion, and the inflow of air comes to $2.5 \times 10^{3} \mathrm{~m}^{3}$ as the results of the two-layer countercurrent velocities (See Fig. 10). These two volumes are roughly equal, and the calorie analysis results prove numerically satisfactory.

\section{Temperature distribution inside tunnel}

The temperature inside the tunnel, which actually represents the gas flow temperature $5 \mathrm{~cm}$ below the upper wall surface, is controlled by the Stanton number (St), which represents the ratio of wall heat transfer coefficient to heat flow. Fig. 6 can be implemented to produce Fig. 12 with its dimensionless quantities, using the temperature at the end of the burned cable, $\mathrm{T}_{0}$, and heat flow thickness, $\delta$ which was $0.8 \mathrm{~m}$. The temperature gradient here is

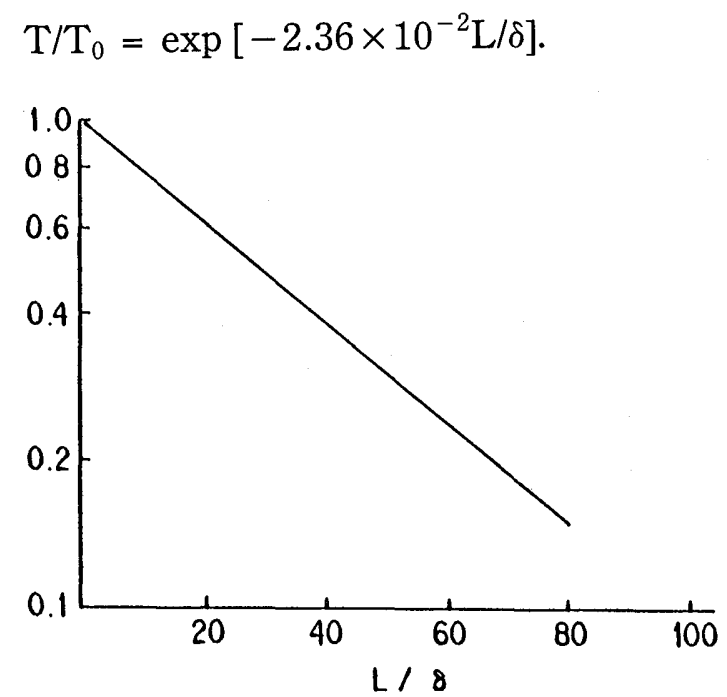

Fig. 12 Tunnel interior dimensionless temperature

Because the volume of air supply in a telecommunications cable tunnel is generally limited, the cable combustion rate is nearly constant, independent of the burning cable volume. This means that the St number is almost constant. This leads to the conclusion that the temperature gradient inside the tunnel is almost constant even in actual tunnels. Moreover, it can be seen that the temperature range above the polyethylene ignition point is located within approximately $40 \mathrm{~m}$, from the end of the burned cable.

\section{CONCLUSION}

Thermocouples were used to investigate tunnel inside temperature distribution caused by polyethylene sheath cable combustion in a full-scale ventilated concrete tunnel. Cal- 
orie-analysis made it clear that more than $80 \%$ of the dissipated calories were absorbed into the tunnel wall, and that between 10 and $20 \%$ of the calories were convected in the gas flow out of the tunnel. This flow contained a large volume of ethylene gas. It was also seen that the temperature gradient inside the tunnel on a log scale could be expressed linearly.

From these observations it can be concluded that for tunnel ventilation rates, cable and fire-proof cable enclosure configurations similar to those studied, the temperature distribution inside the tunnel would be independent of the burning cable volume because of limitations of air-supply, and that temperatures above the polyethylene ignition point would be confined to positions located approximately $40 \mathrm{~m}$ downstream of the burned end of the cables. In addition, fire-proof cable compartment $40 \mathrm{~m}$ in length proved to work effectively.

\section{ACKNOWLEDGEMENT}

Sincere thanks are due to the members of the Fire Research Group of Science University of Tokyo for their kind advice and cooperation during the experiments.

\section{REFERENCES}

(1) T. Handa, O. Sugawa: "Characterization of Flow Behavior of Hot Fire Products in a Concrete Full-scal Corridor", Fire Science and Technology, Vol. 1 (1981).

(2) R. Kitahara, M. Umezu: Study on The Hot-layer Behaviors in Tunnel Fires, Bull of Japanese Assoc. of Science and Engineering, Vol. 34, No. 1 (1984). 